\title{
The Cytotoxic Effect of Cecropin A and Cecropin B on the MDA-MB-231 and M14K Tumour Cell Lines
}

\author{
Radu Anghel1, Daniela Jitaru' ${ }^{2}$, Laurentiu Badescu ${ }^{3}$, Manuela Ciocoiu1 ${ }^{*}$, Magda Badescu ${ }^{1}$ \\ ${ }^{1}$ Department of Pathophysiology, University of Medicine and Pharmacy “Grigore T. Popa”, Iasi, Romania \\ ${ }^{2}$ Laboratory ofMolecular Biology, Regional Institute of Oncology, Iasi, Romania \\ ${ }^{3}$ Department of Cell and Molecular Biology, University of Medicine and Pharmacy "Grigore T. Popa", \\ Iasi, Romania \\ Email: ${ }^{*}$ mciocoiu2003@yahoo.com
}

Received 13 April 2014; revised 28 May 2014; accepted 10 June 2014

Copyright (C) 2014 by authors and Scientific Research Publishing Inc.

This work is licensed under the Creative Commons Attribution International License (CC BY).

http://creativecommons.org/licenses/by/4.0/

(c) () Open Access

\section{Abstract}

The aim of the present in vitro study was to assess the tumoricidal potential of the following natural peptides belonging to the Cecropin family, namely Cecropin $A$ and $B$, on a series of tumour cell lines: MDA-MB-231 (breast adenocarcinoma) and M14K (human mesothelioma). The experimental results reveal that the cytotoxic effects of the two peptides depend on their concentration. Their efficiency is significant at $120 \mu \mathrm{M}$ concentrations and it persists even at $60 \mu \mathrm{M}$ concentrations. The effects were insignificant at $30 \mu \mathrm{M}$ concentrations. On the other hand, the cytotoxic potential was not significantly dependant on the type of peptide but more on the type of tumour cell line used. The MDA-MB-231 line cells were much more sensitive to the action of Cecropins A and B than the M14K line cells. The prospects brought about by this experimental research consist of the collection of in vitro experimental data on the tumoricidal potential of these natural cytotoxic peptides on tumour cells. This will enable specialists to develop future in vivo experimental models in order to test the antitumor effect of these cytotoxic peptides. The ultimate goal would be the discovery of agents with efficient antitumor properties, i.e. with maximum tumoricidal effects and minimum toxic side effects.

\section{Keywords}

Breast Adenocarcinoma, Cecropin A, Cecropin B, Human Mesothelioma, Tumoricidal Potential

\footnotetext{
${ }^{*}$ Corresponding author.
} 


\section{Introduction}

Cytotoxic peptides, also called natural antimicrobial peptides, play an essential role in the immune defence against infections and are present both in plants and insects, and also in superior vertebrates. Each species synthesizes different specific antimicrobial peptides. Both humans and mammals have a large number of antimicrobial peptides involved in nonspecific defence, due both to their microbicidal antibacterial, antifungal and antiviral effect, and to immune modulation [1] [2].

Natural antimicrobial peptides generally have a small molecular weight, i.e. a relatively low number of amino acids, and they are the simplest cell defence mechanism, as they belong to the nonspecific immune system [2] [3]. Their structure is amphipathic and includes two areas, a hydrophilic and a hydrophobic one, placed on both sides of the peptide structure, and the net electric charge is highly positive [3]. The hydrophobic area may interact with the lipids in the microbial membrane, whereas the hydrophilic area interacts with the water or negatively charged structures in the target cell membrane. Nevertheless, normal cells have a cholesterol and neutral lipids rich plasma membrane so they usually remain unharmed [3]. The cationic and amphipathic structure allows the creation of strong electrostatic bonds with the bacteria or fungi cell membranes, or with the coat of certain enveloped viruses [1] [2]. Despite through research, the biochemical mechanisms that the cytotoxic peptide membrane insertion process relies on are not fully known. Therefore there is a need to find new therapeutic agents, considering the frequent resistance to many of the antibiotics currently used in therapy [4] [5].

In addition to the antibacterial activity and immune response modulation activity of these peptides, recent research has shown that some of these cationic peptides have a considerable cytotoxic effect on cancer cells while leaving normal mammal cells unharmed [6] [7]. Most anticancer drugs available today perform tumour growth control only at concentrations that also influence healthy cells, thus leading to undesirable side effects. Hence, it is imperative to find new products with innovative action mechanisms, and one of the current research directions is the use of cytotoxic antimicrobial peptides [8]-[10]. Our study is thus aimed at analyzing the biological effects of some of these peptides, namely Cecropins A and B, on the MDA-MB231—breast adenocarcinoma-and M14K-human mesothelioma-tumour cell lines.

Cecropins A and B were first isolated in the hemolymph of the giant silk moth Hyalophora cecropia. Subsequently, these peptides were also found in mammals [1] [11]. Cecropin A $\left(\mathrm{H}_{2} \mathrm{~N}-\mathrm{Lys}-\mathrm{Trp}-\mathrm{Lys}-\mathrm{Leu}-\mathrm{Phe}-\mathrm{Lys}-\right.$ Lys-Ile-Glu-Lys-Val-Gly-Gln-Asn-Ile-Arg-Asp-Gly-Ile-Ile-Lys-Ala-Gly-Pro-Ala-Val-Ala-Val-Val-Gly-Gln-Al

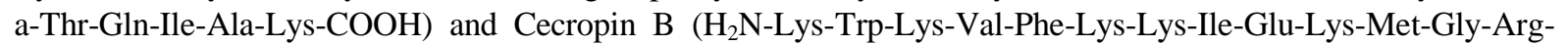
Asn-Ile-Arg-Asn-Gly-Ile-Val-Lys-Ala-Gly-Pro-Ala-Ile-Ala-Val-Leu-Gly-Glu-Ala-Lys-Ala-Leu-COOH) are the most studied antimicrobial peptides belonging to the Cecropin class, as their primary structure includes 34-39 amino acid residues. Both Cecropins have a $\alpha$-helix-like structure. The $\mathrm{NH}_{2}$-terminal end is highly amphipathic, whereas the $\mathrm{COOH}$-terminal end in the $\alpha$-helix is hydrophobic [12] [13]. Due to their ability to form specific amphipathic $\alpha$-helixes, Cecropins act on the non-polar lipid cell membranes and form transmembrane channels that allow free flow of electrolytes, metabolites and water through the phospholipid bilayers, thus leading to irreversible cytolysis and finally to cell death [14]-[16]. In addition to their well-known antimicrobial properties, recent studies have proven the specific antitumor effect of both Cecropin A and Cecropin B on mammal leukaemia, lymphoma and hepatocellular carcinoma cell lines, as well as on other types of tumour cell lines [11] [12] [17].

Therefore, their amino acid composition, amphipathicity, cationic charge and size allow cytotoxic peptides to bind to and penetrate the phospholipid bilayer of the cell membrane, thus forming transmembrane pores, which will alter cell membrane permeability and cause that cell to evolve to apoptosis [15] [18]. Considering all these aspects, our experimental research was aimed at checking the assumption according to which the cytotoxic peptides such as Cecropins A and B have a tumoricidal potential with variable intensity that depends both on the nature of the peptide employed and on its concentration in the living environment of the cells, as well as on the type of cell line chosen for the in vitro experimental study [19] [20].

\section{Materials and Methods}

\subsection{Peptides, Cell Lines and Cell Cultures}

Cecropins A,B, $\geq 97 \%$ (HPLC), $0,1 \%$ TFA in $\mathrm{H}_{2} \mathrm{O}$, Antibiotic peptides from SIGMA product number C6830-1MG lot no 061M4820V for Cecropin A and number C1796-1MG lot no 129K4833 for Cecropin B. Ce- 
cropins are positively charged and amphiphatic. Thought to preferentially bind to anionic phospholipids abundant in bacterial membranes with the formation of dynamic peptide-lipid supramolecular pore and cell permeabilization. Binding to artificial neutral membranes has also been demonstrated.

The peptides under survey (Cecropin A and Cecropin B) were freeze-dried (Sigma) in a RPMI 1640 (Sigma Aldrich) solution ( $\mathrm{pH}=7.35$ ), in a sterile environment. Consecutive peptide dilutions with RPMI 1640 (Sigma Aldrich) were used for the two peptides, whereas the working concentrations were: $120 \mu \mathrm{M}, 60 \mu \mathrm{M}, 30 \mu \mathrm{M}, 15$ $\mu \mathrm{M}, 7.5 \mu \mathrm{M}, 3.5 \mu \mathrm{M}, 1.8 \mu \mathrm{M}, 0.9 \mu \mathrm{M}$ in a final volume of $200 \mu \mathrm{L} /$ well. An optimal and constant number of cells were necessary in each well (final volume of $200 \mu \mathrm{L}$ ) in order to accurately assess the cytotoxic potential because the variable parameter in our study was peptide concentration, for any given peptide and particular cell line. This number of cells was determined by prior research [19], and it was $10^{5}$ tumour cells/well.

Cell cultures are processes by which cells are cultivated in controlled conditions. Cell lines may be grown in adherent or suspension cell cultures. The cytotoxicity of the peptides chosen for this study was assessed on two adherent tumour cell lines: MDA-MB231 (breast adenocarcinoma) and M14K (human mesothelioma).

Both cell lines were cultivated in a RPMI-1640 (Sigma Aldrich) medium with 10\% SFV (Faetal Bovine Serum, GIBCO) [21]. Cell expansion was conducted in $250 \mathrm{~mL}$ flasks in order to get a sufficient number of cells $\left(1 \times 10^{5}\right.$ cells for M14K and MDA-MB-231). The mesothelial cells were detached by trypsination ( 3 minute incubation at $37^{\circ} \mathrm{C}$ with Eurobio trypsin). We used only cells with a viability higher than $97 \%$. The actual testing was performed in plates with 96 flat-bottomed wells each, using a final working volume of $200 \mu \mathrm{L}$ per well. We worked in triplicate for each cell line and for each peptide concentration. The negative control was represented by target cells incubated without peptide. In order to prevent the edge effect and preserve humidity in the plate, only culture medium was pipetted in the edge columns and lines. Viability was analyzed after $72 \mathrm{~h}$ of incubation at $37^{\circ} \mathrm{C}, 5 \% \mathrm{CO}_{2}$, by two methods: MTT [3-(4,5-dimethylthiazol-2-yl)-2,5-diphenyltetrazolium bromide] colorimetric assayand flow cytometry using PE Annexin V (BD Pharmingen) and 7-AAD (7-Aminoactinomycin D).

\subsection{PE Annexin V (BD Pharmingen) and 7-AAD (7-Amino-Actinomycin D) (BD Pharmingen) Viability Assay}

This assay was used to detect and measure the apoptotic process. Apoptosis is characterized by cell morphology changes, nuclear condensation, pyknosis, and also by a series of biochemical events causing mitochondrial membrane and nuclear DNA degradation. Phosphatidylserine, which is normally present in the inner layer of the cell membrane, is exposed at the surface of the cells undergoing various stages of apoptosis. Annexin $\mathrm{V}$ has great affinity to phosphatidylserine residue, and 7-AAD was used as vital nuclear DNA stain. 96 well cell culture plates were used in our study. The first (1) and last (12) column of wells only contained culture medium (RPMI 1640), in order to prevent the edge effect. Columns 2 and 11 of wells only contained peptide-free cell suspension (negative control). Columns 3 - 10 contained target cells and consecutive dilutions of the 2 peptides. We worked in triplicate for the two cell lines and all the peptide concentrations we used. After $72 \mathrm{~h}$ of incubation at $37^{\circ} \mathrm{C}, 5 \% \mathrm{CO}_{2}$, adherent cells were detached by trypsination $\left(3-10\right.$ minute incubation at $37^{\circ} \mathrm{C}$ with Eurobio trypsin). The cell suspension was distributed in such a manner that each FACS (Fluorescence Activated Cell Sorting) tube had $1 \times 10^{5}$ cells. Three FACS tubes were assessed: the first FACS tube contained unmarked cells, the second FACS tube contained Annexin V PE $(10 \mu \mathrm{L} /$ tub FACS tube meaning a $0.1 \mu \mathrm{g} / 200 \mu \mathrm{L}$ cell suspension with $1 \times 10^{5}$ cells) and the third FACS tube contained Annexin V PE/7-AAD. The 7-AAD had the same final concentration like Annexin V PE. Data collection and interpretation were done on a FACS Canto II flow cytometer using the FACSDiva Software (Becton Dickinson) (Figure 1).

\section{3. [3-(4,5-Dimethylthiazol-2-yl)-2,5-Diphenyltetrazolium Bromide] MTT Viability Assay}

The method is based on the ability of succinate dehydrogenase in living cell mitochondria to reduce soluble tetrazolium salts to insoluble red formazan [22]. In order to test viability by this method, the target cells were incubated at $37^{\circ} \mathrm{C}, 5 \% \mathrm{CO}_{2}$, for $72 \mathrm{~h}$, then $20 \mu \mathrm{l}$ of MTT (Sigma, $5 \mathrm{mg} / \mathrm{mL}$ ) were added in each cell well and the incubation at $37^{\circ} \mathrm{C}$ lasted 4 more hours. The medium was then removed and $100 \mu \mathrm{L}$ of DMSO (dimethyl sulfoxide, Roth) were added. Absorbance was measured at $570 \mathrm{~nm}$ against a $620 \mathrm{~nm}$ reference wavelength using a Tecan Sunrise ${ }^{\mathrm{TM}}$ plate reader. Relying on the absorbance values read in the cells incubated with one of the peptides studied ( $\mathbf{A}_{\text {peptide cells }}$ ) and depending on the absorbance value read in peptide-free cells ( $\left.\mathbf{A}_{\text {negative control }}\right)$, we 


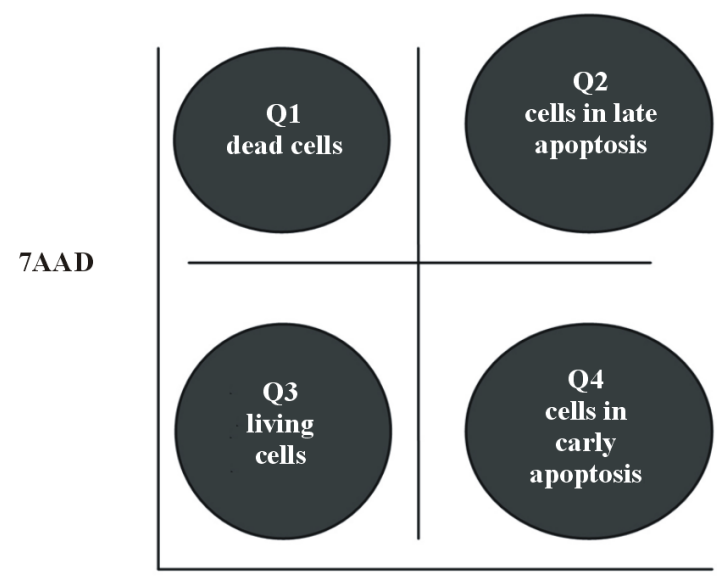

PE Annexin V

Figure 1. Cell viability assessment using flow cytometry, PE Annexin V and 7-AAD. Quadrant Q1 shows the dead cells, Q2-the population of cells in late apoptosis, Q3-the population of living cells, and Q4-the population of cells in early apoptosis [3].

calculated the cytostasis percent, i.e. the percent of cells affected by apoptosis of the whole number of cells in any of the wells analyzed.

$$
\text { cytostasis } \%=\left(\mathbf{1}-\mathbf{A}_{\text {peptide cells }} / \mathbf{A}_{\text {negative control }}\right) \times \mathbf{1 0 0}
$$

The absorbance values used to determine cytostasis were represented by the mean of the three readings for each peptide concentration and each cell line studied.

\section{Results}

One of the main objectives of our research was to assess the cytotoxic potential of Cecropins A and B on certain tumour cell lines, namely MDA-MB231 (breast adenocarcinoma) and M14K (mesothelioma). We also tried to establish whether the cytotoxicity of these peptides belonging to the Cecropin family is influenced by the peptide type or concentration in the cell culture medium or by the type of tumour cell line used.

As far as the MDA-MB231 cell line is concerned, the analysis of the experimental results determined by the MTT viability assay revealed a $32.9 \%$ cytostasis for Cecropin A and a $33.16 \%$ cytostasis for Cecropin B at a $120 \mu \mathrm{M}$ peptide concentration, after $72 \mathrm{~h}$ of incubation with each of the two peptides (Table 1). These results showed that there were no significant differences between the two cecropins as concerns the cytotoxic potential at the same peptide concentration in the culture medium, for the same tumour cell line (MDA-MB231) (Figure 2).

Cytostasis occurred even at a $30 \mu \mathrm{M}$ concentration for both peptides tested, yet it was absent at a $15 \mu \mathrm{M}$ concentration (Table 1). Cytostasis exceeded $20 \%$ for both cecropins in the breast adenocarcinoma tumour line at a $60 \mu \mathrm{M}$ peptide concentration in the culture medium, and it was insignificant at a $30 \mu \mathrm{M}$ concentration.

The absorbance values used to calculate cytostasis were the means of the three readings for each peptide concentration and each cell line analyzed. Form a statistical viewpoint, there were no significant differences between the three readings of the absorbance values.

Flow cytometry allowed apoptosis assessment for the MDA-MB-231 cell line incubated for $72 \mathrm{~h}$ with one of the two peptides. This was achieved by the acquisition of 5000 events/well. The results were compared with the viability of the peptide-free cells (negative control-NC). The cell population distribution analysis revealed that after 72 hours of incubation with cytotoxic peptide more than $50 \%$ of the tumour cells were in the quadrant Q3 (living cells). This was significantly lower than the negative control, for which cell viability was $90.5 \%$ (Figure 3, Table 2).

At a $120 \mu \mathrm{M}$ concentration the tumour cells in the quadrant Q2 underwent apoptosis in a considerable percentage, namely $26.8 \%$ for Cecropin A (CA) and $28.3 \%$ for Ceropin B (CB). Consequently, when the same 
Table 1. The percentage of citostasis (the stop of the cells' proliferation and development until the cell death) was calculated as: $(1-\mathrm{A}) \times 100=\%$ citostasis, where $\mathrm{A}=$ is the ratio between cells' absorbance treated with peptide and absorbance of untreated cells. In this table are given the results for the citostatsis of the human mammary adenocarcionoma line cells incubated for 72 hours with cecropin A and B in RPMI.

\begin{tabular}{cccccccccc}
\hline \multicolumn{7}{c}{ MDA-MB231 tumour cell line cytostasis \% (MTT assay) } \\
\hline $\begin{array}{c}\text { Peptide } \\
\text { concentration }\end{array}$ & $\mathbf{1 2 0} \boldsymbol{\mu M}$ & $\mathbf{6 0} \boldsymbol{\mu M}$ & $\mathbf{3 0} \boldsymbol{\mu M}$ & $\mathbf{1 5} \boldsymbol{\mu M}$ & $\mathbf{7 . 5} \boldsymbol{\mu M}$ & $\mathbf{3 . 5} \boldsymbol{\mu M}$ & $\mathbf{1 . 8} \boldsymbol{\mu M}$ & $\mathbf{0 . 9} \boldsymbol{\mu M}$ \\
Cecropin A & 32.92 & 22.50662 & 5.736981 & -1.67696 & -16.0635 & -19.7705 & -47.1315 & -62.4007 \\
Cecropin B & 33.16 & 25.79263 & 8.56898 & -14.3959 & -50.8141 & -55.2699 & -57.6692 & -58.3548 \\
\hline
\end{tabular}

Table 2. The percentages of living, apoptotic and dead mamary adenocarcinoma cells were determined by flowcytometry, as shown in this table, where Q1 quadrant includes dead cells (7-AAD positive), Q2 quadrant contain late apoptotic (7-AAD positive, AnnexinV positive) and Q4 quadrant contain early apoptotic cells (AnnexinV positive, 7-AAD negative). Viable cells (7-AAD negative, AnnexinV negative) was enclosed in the Q3 quadrant.

\begin{tabular}{|c|c|c|c|c|}
\hline \multirow{2}{*}{$\begin{array}{c}\text { MDA-MB231 } \\
5000 \text { events/well }\end{array}$} & $\begin{array}{l}\text { Q1-dead } \\
\text { cells-7AAD+ }\end{array}$ & $\begin{array}{l}\text { Q2-cells in late apoptosis- } \\
\text { 7AAD+AnnexinV+ }\end{array}$ & $\begin{array}{l}\text { Q3-living cells- } \\
\text { 7AAD-AnnexinV- }\end{array}$ & $\begin{array}{l}\text { Q4-cells in early apoptosis- } \\
\text { AnnexinV+7AAD- }\end{array}$ \\
\hline & $\%$ & $\%$ & $\%$ & $\%$ \\
\hline Negative cotrol (NC) & 1.2 & 3.6 & 90.5 & 4.7 \\
\hline $\begin{array}{l}\text { Cecropin A } 120 \mu M \\
\text { (CA120) }\end{array}$ & 1.3 & 26.8 & 64.4 & 7.5 \\
\hline $\begin{array}{c}\text { Cecropin A } 60 \mu M \\
\text { (CA60) }\end{array}$ & 1.4 & 14. 9 & 76.1 & 7.6 \\
\hline $\begin{array}{l}\text { Cecropin B } 120 \mu M \\
\text { (CB120) }\end{array}$ & 1.5 & 28.3 & 63.8 & 6.4 \\
\hline $\begin{array}{c}\text { Cecropin B } 60 \mu M \\
\text { (CB60) }\end{array}$ & 1.4 & 17.6 & 77.3 & 3.7 \\
\hline
\end{tabular}

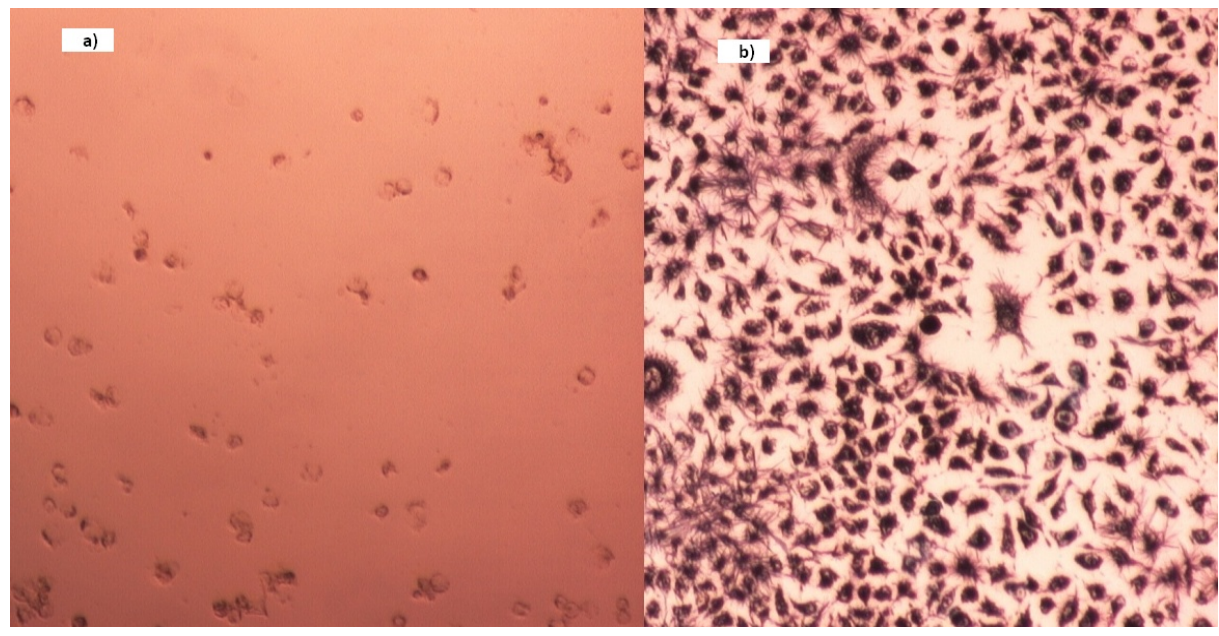

Figure 2. a) MDA-MB 231 cell line after 72 h of incubation with cytotoxic peptide (Cecropin B);

b) MDA-MB231 cell culture after $72 \mathrm{~h}$ of peptide-free cultivation-negative control (NC). The photo was taken after MTT had been added by a Nikon Eclipse TE 300 microscope (100× lens).

peptide concentration and tumour cell line were used, there were no statistically significant differences as concerns cell viability as compared to the negative control, which included only $3.6 \%$ late apoptosis cells (quadrant Q2) (Figure 4, Table 2). The late apoptosis cell percentage dropped considerably with the halving of the peptide concentration in the cell culture environment. The results attained by this technique were also supported by the MTT assay.

The M14K cell line is an adherent human mesothelioma cell line. Mesothelioma is a very aggressive malignant tumour, which occurs on surfaces covered with mesothelial cells, most commonly in pleural cavities, but 


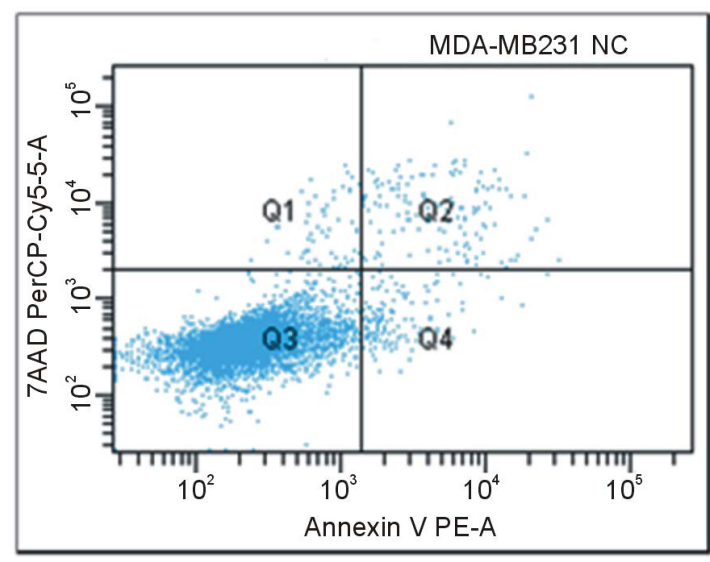

(a)

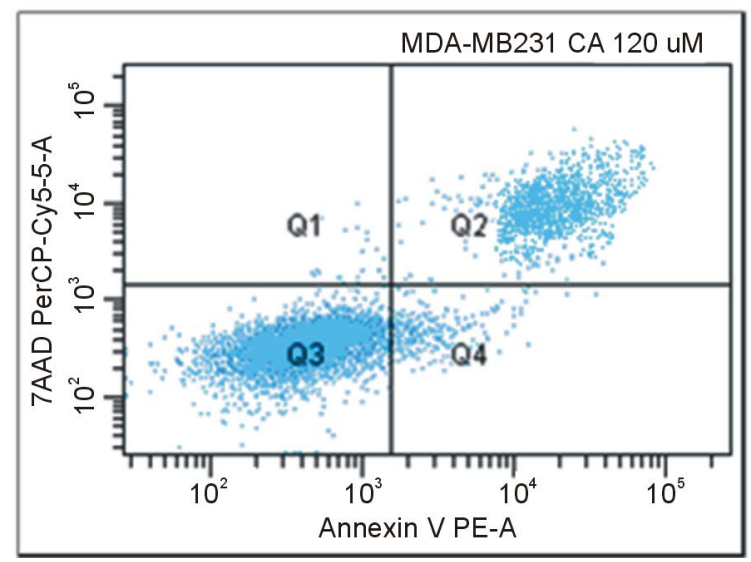

(b)

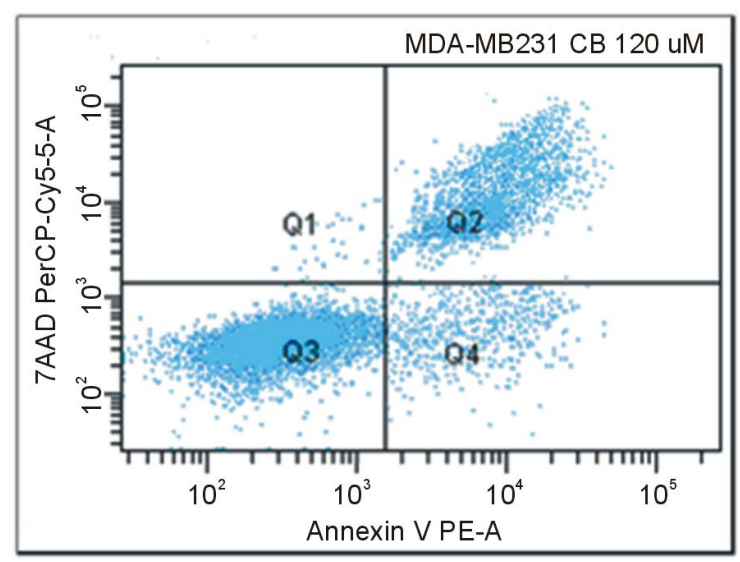

(c)

Figure 3. Distribution according to the fluorescence intensity of the 7-AAD and Annexin V labeling of the MBA-MB-231 cells in the absence of a cytotoxic peptide-Negative Control (NC) when cell viability was $90.5 \%$ (a) and in the presence of the cytotoxic peptide $(120 \mu \mathrm{M})$ after incubation for 72 hours in RPMI when living cells was $64.4 \%$ for Cecropin A (b) and $63.8 \%$ for Cecropin B (c). The percentages of living, apoptotic and dead mamary adenocarcinoma cells were determined by flowcytometry, as shown in this figure, where Q1 quadrant includes dead cells (7-AAD positive), Q2 quadrant contain late apoptotic (7-AAD positive, AnnexinV positive) and Q4 quadrant contain early apoptotic cells (AnnexinV positive, 7-AAD negative). Viable cells (7-AAD negative, AnnexinV negative) was enclosed in the Q3 quadrant.

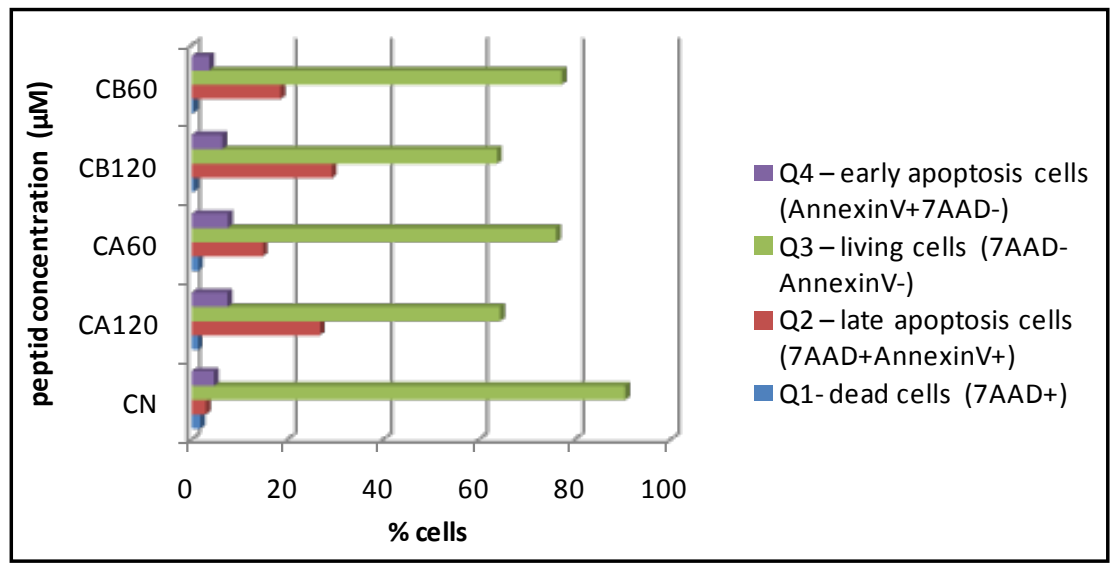

Figure 4. Assessment of MDA-MB-231 cell apoptosis in the presence or absence of the studied cytotoxic peptides: Magainin II (M), Cecropin A (CA) and Cecropin B (CB) at $120 \mu \mathrm{M}$ and $60 \mu \mathrm{M}$ concentrationsafter incubation for 72 hours in RPMI. 
also in the peritoneum, pericardium and soft paratesticular tissues. As its metastasis potential amounts to $75 \%$ of the patients and its response rate to various chemotherapeutic agents is below $20 \%$, mesothelial cells are an adequate target for the assessment of new chemotherapeutic agents [23] [24]. Among the 3 histological subtypes of mesothelioma, our experiment used the M14K mesothelial epithelial cell line.

After $72 \mathrm{~h}$ of incubation of the M14K cell line, optical microscopy revealed that the mesothelioma cells underwent apoptosis as compared to the negative control (NC-M14K cells incubated without peptide) (Figure 5(a), Figure 5(b)).

The images of the optical microscope were also confirmed by the MTT viability assay. The absorbance values were read (we worked in triplicate), their mean was determined and the cytostasis for each cecropin concentration used for the M14K line cell incubation was calculated (Table 3).

The percentage of cells undergoing apoptosis in the presence of one of the two cecropins was smaller than that of the MDA-MB 231 cell line. Cytostasis was $26.3 \%$ when Cecropin A was used and $22.56 \%$ when Cecropin B was used, at a $120 \mu \mathrm{M}$ peptide concentration in the cell culture medium (Table 3). The cytostasis percentage dropped significantly with the decrease of the peptide concentration, and was absent at $15 \mu \mathrm{M}$ concentrations (Table 3).

Another peptide cytotoxicity assessment technique was flow cytometry, which enabled us to assess cell apoptosis in the presence or absence of peptide at different peptide concentrations (Figure 6). The cell populations were divided in four quadrants, namely living cell population (Q3), early apoptosis cell population (Q4) late apoptosis cell population (Q2) and dead cell population (Q1) (Figure 6). According to this technique, the evolution of the M14K cells on their impact with the two types of cytotoxic peptides after 72 hours of incubation was significantly different from the evolution of the MDA-MB-231 cells (Figure 4, Figure 7). The M14K line tumour cells proved more resistant to Cecropins A and B after 72 hours at a $120 \mu \mathrm{M}$ concentration, since they

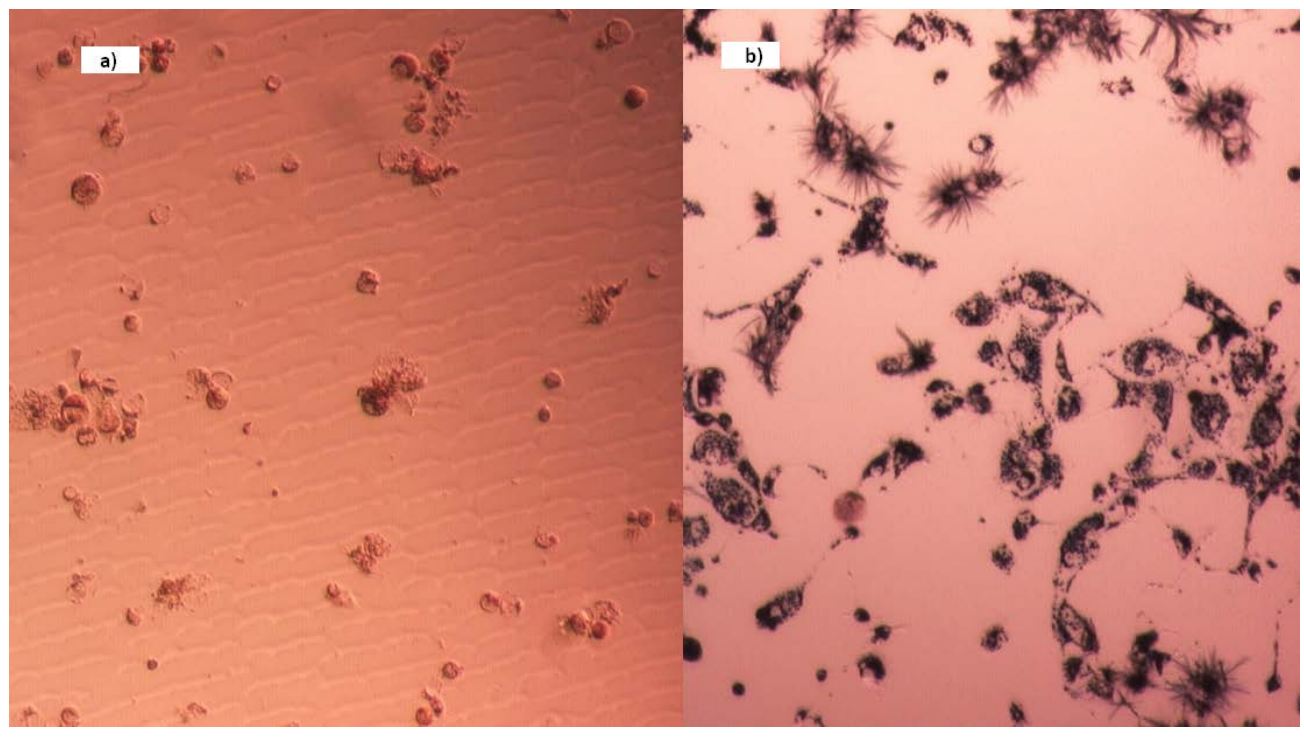

Figure 5. a) M14K line cells after $72 \mathrm{~h}$ of peptide (Cecropin A) incubation; b) M14K cell culture after $72 \mathrm{~h}$ of peptide-free cultivation-NC, negative control (about $20 \mu \mathrm{m}$ cell diameter). The photo was taken after MTT had been added to the M14K line cells after the latter's peptide incubation, by a Nikon Eclipse TE 300 microscope (100× lens).

Table 3. The results for the citostatsis (\%) of the human mesotelioma line cells incubated for 72 hours with cecropin A and $\mathrm{B}$ in RPMI.

\begin{tabular}{ccccccccc}
\hline \multicolumn{7}{c}{ M14K tumour cell line cytostasis \% (MTT assay) } \\
\hline $\begin{array}{c}\text { Peptide } \\
\text { concentration }\end{array}$ & $\mathbf{1 2 0} \boldsymbol{\mu M}$ & $\mathbf{6 0} \boldsymbol{\mu M}$ & $\mathbf{3 0} \boldsymbol{\mu M}$ & $\mathbf{1 5} \boldsymbol{\mu M}$ & $\mathbf{7 . 5} \boldsymbol{\mu M}$ & $\mathbf{3 . 5} \boldsymbol{\mu M}$ & $\mathbf{1 . 8} \boldsymbol{\mu M}$ & $\mathbf{0 . 9} \boldsymbol{\mu M}$ \\
Cecropin A & 26.33 & 17.79359 & 5.071174 & -11.3879 & -31.5836 & -41.9039 & -51.7794 & -63.0783 \\
Cecropin B & 22.56 & 13.9207 & 3.788546 & -8.54626 & -23.5242 & -45.2863 & -59.5595 & -62.5551 \\
\hline
\end{tabular}




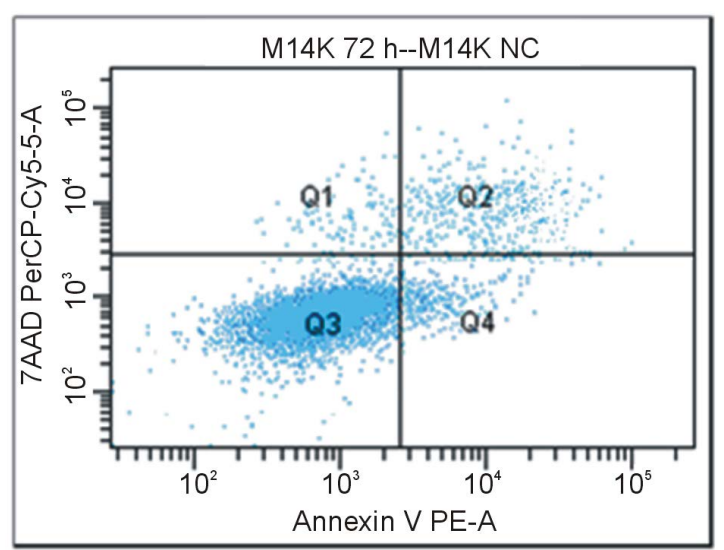

(a)

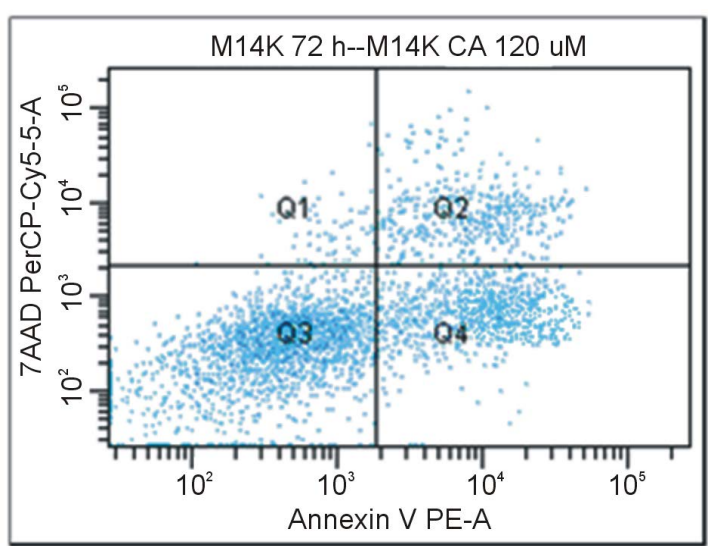

(b)

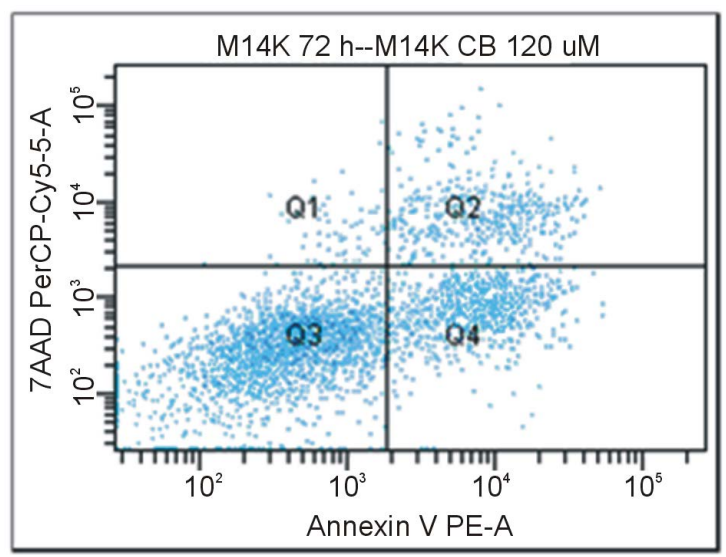

(c)

Figure 6. Distribution according to the fluorescence intensity of the 7-AAD and Annexin V labeling of the M14K cells in the absence of a cytotoxic peptide-Negative Control (NC) when cell viability was $89.6 \%$ (a) and in the presence of the cytotoxic peptide $(120 \mu \mathrm{M})$ after incubation for 72 hours in RPMI when living cells was $73.6 \%$ for Cecropin A (b) and $73.0 \%$ for Cecropin B (c). The percentages of living, apoptotic and dead human mesotelioma cells were determined by flowcytometry, as shown in this figure, where Q1 quadrant includes dead cells (7-AAD positive), Q2 quadrant contain late apoptotic (7-AAD positive, AnnexinV positive) and Q4 quadrant contain early apoptotic cells (AnnexinV positive, 7-AAD negative). Viable cells (7-AAD negative, AnnexinV negative) was enclosed in the Q3 quadrant.

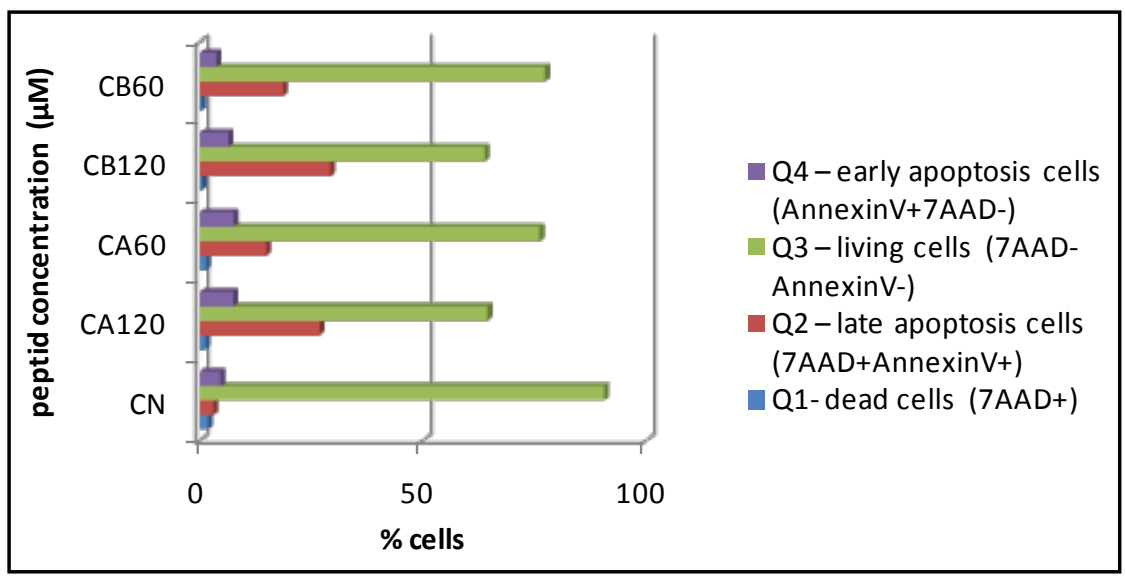

Figure 7. Assessment of MDA-MB-231 cell apoptosis in the presence or absence of the studied cytotoxic peptides: Magainin 2 (M), Cecropin A (CA) and Cecropin B (CB) at $120 \mu \mathrm{M}$ and $60 \mu \mathrm{M}$ concentrations. 
were in the initial apoptosis stage (quadrant Q4), unlike the MDA-MB231 line cells which were already in a process of late apoptosis (quadrant Q2). On the other hand, the much lower M14K cell sensitivity to the action of these peptides is also supported by the fact that the cell percentage in quadrant Q4 did not exceed 20\% (17.4\% for Cecropin A and 18.3\% for Cecropin B). The percentage of M14K line tumour cells in quadrant Q2 was below $10 \%$ on the average (6.6\% for Cecropin A and 6.9 for Cecropin B) (Figure 7, Table 4).

Cell viability was significantly high with the decrease of the culture medium peptide concentration (at $60 \mu \mathrm{M})$. Cell apoptosis was insignificant at $30 \mu \mathrm{M}$ and absent at $15 \mu \mathrm{M}$ peptide concentrations (Table 3). The experimental results achieved by flow cytometry, which analyzed the apoptosis of the cells of the M14K line incubated with the studied peptides in different concentrations specified in the work plan, were supported by the MTT technique.

The two cell lines, namely MDA-MB-231 (breast adenocarcinoma) and M14K (human mesothelioma), behaved differently under the action of Cecropins A and B. The MDA-MB-231 line was more sensitive to their action than the M14K line. We may therefore argue that different types of tumour cells behave differently under the action of the same cytotoxic peptides at similar concentrations.

\section{Discussion}

The mechanism by which cytotoxic peptides are operational depends on a number of physical-chemical characteristics such as: primary sequence, secondary structure, net electric charge, amphipathicity, hydrophobicity as well as their concentration in the biomembrane and cell membrane composition [25].

The currently accepted model, by which antimicrobial peptides prove their functionality, involves the existence of several consecutive stages such as: peptide association on the membrane surface, peptide gathering in secondary structures defined on the membrane surface, peptide insertion in the biomembranes and finally transmembrane pore formation [11] [15] [26]. The changes occurring in the cell membrane have major implications in infection progression as they play a key role in the cell's response to its environment [27] [28].

The analysis of the interactions between cytotoxic peptides and lipid membranes may reveal both the conditions in which the membranes are sensitive to the action of these peptides, and the possible means of rendering their selectivity more efficient [29]-[34]. The determining factors are influenced, on one hand, by the characteristics of the biologic environment where these interactions occur and, on the other hand, by the characteristics of the membrane, i.e. the type of lipid molecules making up the membrane structure that directly influences the electric profile of the membrane, as well as its fluidity [35]-[39]. Understanding these factors is vital for research done on the synthesis of peptides with better selectivity and specificity [35] [37] [39].

Two distinct types of ion channels formed by cytotoxic peptide aggregation have been described so far: classical pores, with an interior made only of the polar parts of the peptides, and toroidal pores, that also includes the polar ends of the lipids in the cell membrane [9] [36] [38] [39]. The progressive addition of new monomers (cytotoxic peptides) will broaden the pores and finally lead to the dispersion or infiltration of the content of a cell

Table 4. The percentages of living, apoptotic and dead mesotelioma cells were determined by flowcytometry, as shown in this table, where Q1 quadrant includes dead cells (7-AAD positive), Q2 quadrant contain late apoptotic (7-AAD positive, AnnexinV positive) and Q4 quadrant contain early apoptotic cells (AnnexinV positive, 7-AAD negative). Viable cells (7-AAD negative, AnnexinV negative) was enclosed in the Q3 quadrant.

\begin{tabular}{|c|c|c|c|c|}
\hline \multirow{2}{*}{$\begin{array}{c}\text { M14K } \\
5000 \text { events/well }\end{array}$} & $\begin{array}{c}\text { Q1 } \\
\text { (7AAD+) }\end{array}$ & $\begin{array}{c}\text { Q2 } \\
\text { (7AAD+AnnexinV+) }\end{array}$ & $\begin{array}{c}\text { Q3 } \\
\text { (7AAD-AnnexinV-) }\end{array}$ & $\begin{array}{c}\text { Q4 } \\
\text { (AnnexinV+7AAD-) }\end{array}$ \\
\hline & $\%$ & $\%$ & $\%$ & $\%$ \\
\hline Negative control (NC) & 2.1 & 3.8 & 89.6 & 4.5 \\
\hline $\begin{array}{l}\text { Cecropin A } 120 \mu M \\
\text { (CA120) }\end{array}$ & 2.4 & 6.6 & 73.6 & 17.4 \\
\hline $\begin{array}{c}\text { Cecropin A } 60 \mu M \\
\text { (CA60) }\end{array}$ & 2.2 & 4.1 & 81.1 & 12.6 \\
\hline $\begin{array}{l}\text { Cecropin B } 120 \mu M \\
\text { (CB120) }\end{array}$ & 1.8 & 6.9 & 73 & 18.3 \\
\hline $\begin{array}{c}\text { Cecropin B } 60 \mu M \\
\text { (CB60) }\end{array}$ & 1.1 & 4.2 & 84.3 & 10.4 \\
\hline
\end{tabular}


and hence to its death [9] [35]-[39]. By forming ion channels, these cytotoxic peptides can permeabilise the cell membrane, can induce $\mathrm{K}^{+}$and other cell components efflux and finally triggering apoptosis [29] [36]-[38].

Although the precise mechanism of antimicrobial peptide action is still controversial, specialists agree on one thing, namely that these peptides distort cell membranes selectively and that the structural amphipathic peptide layout is thought to play an important role in this mechanism [5] [7] [8] [15]. Thus, the biological effect of potentially cytotoxic natural peptides on tumour cells may be studied both on an animal experimental models and on tumour cell lines [2] [7] [8].

Considering all these issues discussed by literature, our experimental research analyzed the assumption according to which cytotoxic peptides such as Cecropins A and B have a tumoricidal potential with variable intensity dependent on the nature of the peptide used and on its concentration in the cell living environment, as well as on the type of cell line chosen for the in vitro experimental study. In order to underline these phenomena, we reckoned that $10^{5}$ cells/well in a final culture environment volume of $200 \mu \mathrm{L}$ [19] would be the optimal cell concentration necessary to assess the cytotoxic potential of the peptides studied.

The objectives of our research were fulfilled by the assessment of the in vitro cytotoxic effect (with the aid of the MTT technique) using the cytostasis percentage in various types of cells (MDA-MB-231 and M14K cell lines). This cell viability monitoring technique in the presence of a supposedly toxic compound was confirmed by the flow cytometry technique using the 7AAD and PE Annexin V fluorochromes. This technique was also employed to determine the apoptosis stage of the tumour cells after 72 hours of incubation in the presence of a peptide. The results obtained were also compared with the negative control (tumour cells incubated in the absence of peptides).

\section{Conclusions}

The cytotoxic effect of the two peptides belonging to the Cecropin family depended on their concentration in the living environment of the tumour cells, being significant at $120 \mu \mathrm{M}$ concentrations and persisting even at $60 \mu \mathrm{M}$ concentrations. These tumoricidal effects were insignificant at $30 \mu \mathrm{M}$ concentrations. According to literature, the cytotoxic potential depends on the type of peptide. The toxicity of the same concentration of the two cecropins was similar for the same tumour line. Another conclusion of this study would be that the tumoricidal effect also depends on the type of tumour cell line. The results revealed that the MDA-MB-231 line cells (breast adenocarcinoma) were much more sensitive to Cecropins A and B than the M14K tumour line cells (human mesothelioma).

The prospects brought about by this experimental research consist of the collection of in vitro experimental data on the tumoricidal potential of these natural cytotoxic peptides on tumour cells. This will enable specialists to develop future in vivo experimental models in order to test the antitumor effect of these cytotoxic peptides. The ultimate goal would be the discovery of agents with efficient antitumor properties, i.e. with maximum tumoricidal effect and minimum toxic side effects.

\section{References}

[1] Hoskin, D.W. and Ramamoorthy, A. (2008) Studies on Anticancer Activities of Antimicrobial Peptides. Biochimica et Biophysica Acta (BBA), 1778, 357-375. http://dx.doi.org/10.1016/j.bbamem.2007.11.008

[2] Reddy, K.V.R., Yedery, R.D. and Aranha, C. (2004) Antimicrobial Peptides: Premises and Promises. International Journal of Antimicrobial Agents, 24, 536-547. http://dx.doi.org/10.1016/j.ijantimicag.2004.09.005

[3] Dennison, S.R., Whittaker, M., Harris, F. and Phoenix, D.A. (2006) Anticancer Alpha-Helical Peptides and Structure/Function Relationships Underpinning Their Interactions with Tumour Cell Membranes. Current Protein \& Peptide Science, 7, 487-499. http://dx.doi.org/10.2174/138920306779025611

[4] Braff, M.H., Zaiou, M., Fierer, J., Nizet, V. and Gallo, R.L. (2005)Keratinocyte Production of Cathelicidin Provides Direct Activity Against Bacterial Skin Pathogens. Infection and Immunity, 73, 6771-6781. http://dx.doi.org/10.1128/IAI.73.10.6771-6781.2005

[5] Mor, A. (2000) Peptide-Based Antibiotics: A Potential Answer to Raging Antimicrobial Resistance. Drug Development Research, 50, 440-447. http://dx.doi.org/10.1002/1098-2299(200007/08)50:3/4<440::AID-DDR27>3.0.CO;2-4

[6] Hilchie, A., Doucette, C.D., Pinto, D., Patrzykat, A., Douglas, S. and Hoskin, D.W. (2011) Pleurocidin-Family Cationic Antimicrobial Peptides Are Cytolytic for Breast Carcinoma Cells and Prevent Growth of Tumor Xenografts. Breast Cancer Research, 13, R102. http://dx.doi.org/10.1186/bcr3043 
[7] Seth, B.C. and Scandurro, A.B. (2008) Tumors Sound the Alarmin(s). Cancer Research, 68, 6482-6485. http://dx.doi.org/10.1158/0008-5472.CAN-08-0044

[8] Chamorro, C.I., Weber, G., Grönberg, A., Pivarcsi, A. and Ståhle, M. (2009) The Human Antimicrobial Peptide LL-37 Suppresses Apoptosis in Keratinocytes. Journal of Investigative Dermatology, 129, 937-944. http://dx.doi.org/10.1038/jid.2008.321

[9] Koczulla, A.R. and Bals, R. (2003) Antimicrobial Peptides-Current Status and Therapeutics Potential. Drugs, 63, 389406. http://dx.doi.org/10.2165/00003495-200363040-00005

[10] Rosenfeld, Y. and Shai, Y. (2006) Lipopolysaccharide (Endotoxin)-Host Defense Antibacterial Peptides Interactions: Role in Bacterial Resistance and Prevention of Sepsis. BBA-Biomembranes, 1758, 1513-1522. http://dx.doi.org/10.1016/j.bbamem.2006.05.017

[11] Suttmann, H., Retz, M., Paulsen, F., Harder, J., Zwergel, U., Kamradt, J., et al. (2008) Antimicrobial Peptides of the Cecropin-Family Show Potent Antitumor Activity Against Bladder Cancer Cells. BMC Urology, 8, 5. http://dx.doi.org/10.1186/1471-2490-8-5

[12] Chan, S.C., Hui, L. and Chen, H.M. (1998) Enhancement of the Cytolytic Effect of Anti-Bacterial Cecropin by the Microvilli of Cancer Cells. Anticancer Research, 18, 4467-4474.

[13] Moore, A.J., Devine, D.A. and Bibby, M.C. (1994) Preliminary Experimental Anticancer Activity of Cecropins. Peptide Research, 7, 265-269.

[14] Chen, H.M., Wang, W., Smith, D. and Chan, S.C. (1997) Effects of the Anti-Bacterial Peptide Cecropin B and Its Analogs, Cecropins B-1 and B-2, on Liposomes, Bacteria, and Cancer Cells. Biochimica et Biophysica Acta, 1336, 171-179. http://dx.doi.org/10.1016/S0304-4165(97)00024-X

[15] Sato, H. and Feix, J.B. (2006) Peptide-Membrane Interactions and Mechanisms of Membrane Destruction by Amphipathic $\alpha$-Helical Antimicrobial Peptides. BBA, 9, 1245-1256. http://dx.doi.org/10.1016/j.bbamem.2006.02.021

[16] Silvestro, L., Weiser, J.N. and Axelsen, P.H. (2000) Antibacterial and Antimembrane Activities of Cecropin A in Escherichia coli. Antimicrobial Agents and Chemotherapy, 44, 602-607. http://dx.doi.org/10.1128/AAC.44.3.602-607.2000

[17] Jin, X.B., Mei, H.F., Li, X.B., Ma, Y., Zeng, A.H., Wang, Y., Lu, X., Chu, F., Wu, Q. and Zhu, J.Y. (2010) ApoptosisInducing Activity of the Antimicrobial Peptide Cecropin of Musca domestica in Human Hepatocelular Carcinoma Cell Line BEL-7402 and the Possible Mechanism. Acta Biochimica et Biophysica Sinica, 42, 259-265. http://dx.doi.org/10.1093/abbs/gmq021

[18] Kourie, J.I. and Shorthouse, A.A. (2000) Properties of Cytotoxic Peptide-Formed Ion Channels. American Journal of Physiology. Cell Physiology, 278, C1063-C1087.

[19] Anghel, R., Jitaru, D., Badescu, L., Badescu, M. and Ciocoiu, M. (2013) The Cytotoxic Effect of Magainine II on the MDA-MB-231 and M14K Tumor Cell Lines. BioMed Research International, 2013, Article ID: 831709.

[20] Pascariu, M., Anghelache, N., Constantinescu, D., Jitaru, D., Carasevici, E. and Luchian, T. (2011) The Evaluation of Biological Effect of Cytotoxic Peptides on Tumor Cell Lines. Digest Journal of Nanomaterials and Biostructures, 7, 79-84.

[21] Masters, J.R. and Stacey, G.N. (2007) Changing Medium and Passaging Cell Lines. Nature Protocols, 2, $2276-2284$. http://dx.doi.org/10.1038/nprot.2007.319

[22] Ohno, T., Asakura, M., Awogi, T., Futamura,Y., Harihara, A., Hatao, M., Hayasaka, A. and Hayashi, M. (1998) Validation Study on Five Cytotoxicity Assays by JSAAE-VII. Details of the MTT Assay. Alternative Animal Test Experiment, 5, 1-38.

[23] Baas, P. (2002) Chemotherapy for Malignant Mesothelioma: From Doxorubicin to Vinorelbine. Seminars in Oncology, 29, 62-69. http://dx.doi.org/10.1053/sonc.2002.30231

[24] Moskal, T.L., Urschel, J.D., Anderson, T.M., Antkowiak, J.G. and Takita, H. (1998) Malignant Pleural Mesothelioma: A Problematic Review. Surgical Oncology, 7, 5-12. http://dx.doi.org/10.1016/S0960-7404(98)00019-X

[25] Adams, J.S., Ren, S., Liu, P.T., Chun, R.F., Lagishetty, V., Gombart, A.F., Borregaard, N., Modlin, R.L. and Hewison, M. (2009) Vitamin D-Directed Rheostatic Regulation of Monocyte Antibacterial Responses. Journal of Immunology, 182, 4289-4295. http://dx.doi.org/10.4049/jimmunol.0803736

[26] Chromek, M., Slamová, Z., Bergman, P., Kovács, L., Podracká, L., Ehrén, I., Hökfelt, T., Gudmundsson, G.H., Gallo, R.L., Agerberth, B. and Brauner, A. (2006) The Antimicrobial Peptide Cathelicidin Protects the Urinary Tract against Invasive Bacterial Infection. Nature Medicine, 12, 636-641. http://dx.doi.org/10.1038/nm1407

[27] Nizet, V., Ohtake, T., Lauth, X., Trowbridge, J., Rudisill, J., Dorschner, R.A., Pestonjamasp, V., Piraino, J., Huttner, K. and Gallo, R.L. (2001) Innate Antimicrobial Peptide Protects the Skin from Invasive Bacterial Infection. Nature, 414, 454-457. http://dx.doi.org/10.1038/35106587 
[28] Schauber, J., Dorschner, R.A., Yamasaki, K., Brouha, B. and Gallo, R.L. (2006) Control of the Innate Epithelial Antimicrobial Response Is Cell-Type Specific and Dependent on Relevant Microenvironmental Stimuli. Immunology, 118, 509-519.

[29] Brogden, K.A. (2005) Antimicrobial Peptides: Pore Formers or Metabolic Inhibitors in Bacteria? Nature Reviews Microbiology, 3, 238-250. http://dx.doi.org/10.1038/nrmicro1098

[30] Cantor, R.S. (2002) Size Distribution of Barrel-Stave Aggregates of Membrane Peptides: Influence of the Bilayer Lateral Pressure Profile. Biophysical Journal, 82, 2520-2525. http://dx.doi.org/10.1016/S0006-3495(02)75595-1

[31] Golec, M. (2007) Cathelicidin LL-37: LPS-Neutralizing, Pleiotropic Peptide. Annals of Agricultural and Environmental Medicine, 14, 1-4.

[32] Schmidtchen, A., Frick, I.M., Andersson, E., Tapper, H. and Björck, L. (2002) Proteinases of Common Pathogenic Bacteria Degrade and Inactivate the Antibacterial Peptide LL-37. Molecular Microbiology, 46, 157-168. http://dx.doi.org/10.1046/j.1365-2958.2002.03146.x

[33] Sorensen, O.E., Follin, P., Johnsen, A.H., Calafat, J., Tjabringa, G.S., Hiemstra, P.S. and Borregaard, N. (2001) Human Cathelicidin, hCAP-18, Is Processed to the Antimicrobial Peptide LL-37 by Extracellular Cleavage with Proteinase 3. Blood, 97, 3951-3959. http://dx.doi.org/10.1182/blood.V97.12.3951

[34] Yang, L., Harroun, T.A., Weiss, T.M., Ding, L. and Huang, H.W. (2001) Barrel-Stave Model or Toroidal Model? A Case Study on Melittin Pores. Biophysical Journal, 81, 1475-1485. http://dx.doi.org/10.1016/S0006-3495(01)75802-X

[35] Dhople, V., Krukemeyer, A. and Ramamoorthy, A. (2006) The Human Beta-Defensin-3, an Antibacterial Peptide with Multiple Biological Functions. Biochimica et Biophysica Acta, 1758, 1499-1512. http://dx.doi.org/10.1016/j.bbamem.2006.07.007

[36] Lee, D.K., Brender, J.R., Sciacca, M.F.M., Krishnamoorthy, J., Yu, C. and Ramamoorthy, A. (2013) Lipid CompositionDependent Membrane Fragmentation and Pore-Forming Mechanisms of Membrane Disruption by Pexiganan (MSI-78). Biochemistry, 52, 3254-3263. http://dx.doi.org/10.1021/bi400087n

[37] Ramamoorthy, A., Thennarasu, S., Lee, D.K., Tan, A. and Maloyy, L. (2006) Solid-State NMR Investigation of the Membrane-Disrupting Mechanism of Antimicrobial Peptides MSI-78 and MSI-594 Derived from Magainin 2 and Melittin. Biophysical Journal, 91, 206-216. http://dx.doi.org/10.1529/biophysj.105.073890

[38] Ramamoorthy, A. (2009) Beyond NMR Spectra of Antimicrobial Peptides: Dynamical Images at Atomic Resolution and Functional Insights. Solid State Nuclear Magnetic Resonance, 35, 201-207. http://dx.doi.org/10.1016/j.ssnmr.2009.03.003

[39] Thennarasu, S., Huang, R., Lee, D.K., Yang, P., Maloy, L., Chen, Z. and Ramamoorthy, A. (2010) Limiting an Antimicrobial Peptide to the Lipid-Water Interface Enhances Its Bacterial Membrane Selectivity: A Case Study of MSI-367. Biochemistry, 49, 10595-10605. http://dx.doi.org/10.1021/bi101394r 
Scientific Research Publishing (SCIRP) is one of the largest Open Access journal publishers. It is currently publishing more than 200 open access, online, peer-reviewed journals covering a wide range of academic disciplines. SCIRP serves the worldwide academic communities and contributes to the progress and application of science with its publication.

Other selected journals from SCIRP are listed as below. Submit your manuscript to us via either submit@scirp.org or Online Submission Portal.
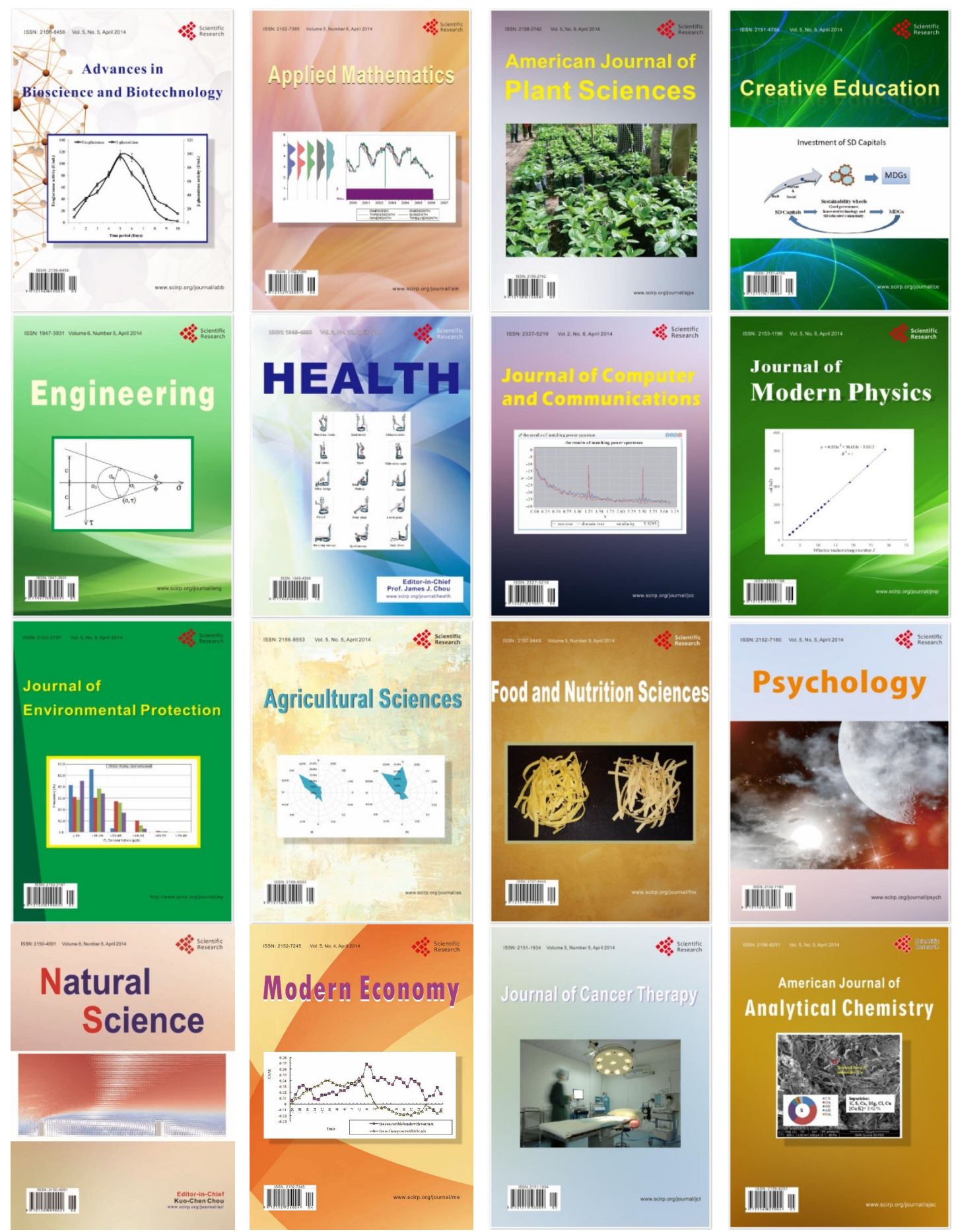